\title{
Health and Thermal Comfort: From WHO guidance to
}

\section{housing strategies}

\author{
David Ormandy * and Véronique Ezratty *\# \\ * WHO Collaborating Centre for Housing Standards and Health, \\ Institute of Health, University of Warwick, UK \\ \# Service des Etudes Médicales d'EDF, Levallois-Perret, France
}

Corresponding Author -

David Ormandy

email -david.ormandy@warwick.ac.uk

Telephone - +44 (0) 2476524936

Postal Address - WHO Collaborating Centre for Housing Standards and Health

Institute of Health

University of Warwick

Coventry

CV4 7AL

UK 


\section{Abstract}

There are many references to the WHO guidance on thermal comfort in housing, but not to the original source material. Based on archive material, this paper gives the evidential basis for the WHO guidance. It then reports on evidence that some groups may be more susceptible to high or low indoor temperatures than others. It examines different methods for measuring thermal comfort, such as air temperature measurement, assessing resident's perception, and predicting satisfaction. Resident's perception was used effectively in the WHO LARES project, showing that self-reported poor health was significantly associated with poor thermal comfort.

Tools to inform strategies directed at dealing with cold homes and fuel poverty are considered, including Energy Performance Certificates, Fuel Poverty Indicators, and the English Housing Health and Safety Rating System. Conclusions from a WHO Workshop on Housing, Energy and Thermal Comfort are also summarised.

The WHO view of thermal comfort, which is driven by protecting health from both high and low indoor temperatures, should be recognised in energy efficiency, fuel poverty and climate change strategies. While this is a major challenge, it could provide both health gains for individuals, and economic benefits for society.

Keywords - Health, Thermal Comfort, Housing 


\section{Introduction}

While the term 'thermal comfort' is used to cover a variety of circumstances, the World Health Organization's guidance on thermal comfort is not just about ensuring a sensation of satisfaction with the ambient temperature, it is inextricably linked to health. It is guidance for the home environment, and aimed at protecting health, particularly the health of those most susceptible and fragile to temperatures outside that range, such as the very young, and older people.

Guidance should not just be theoretical and aspirational. As well as being capable of being met, practical means of measuring and predicting that the guidance is satisfied are needed. Measuring air temperature may seem the obvious approach, but this is not always practical or reliable, so alternative methods have been developed. While not necessarily providing exact measurements of temperature, they give an indication of thermal comfort. But the limitations of these methods need to be recognised.

There is also a need for mechanisms to estimate where meeting the temperature range will be difficult or unlikely, and for identifying potentially susceptible occupiers. These mechanisms can help focus preventative and remedial strategies.

We review the evidence supporting the WHO guidance on thermal comfort, the means for measuring and predicting that it is being met, and some tools used to inform strategies. 


\section{Thermal Comfort - the WHO Guidelines}

\subsection{Background}

Thermal Comfort is influenced by a range of environmental and individual objective, and subjective factors. The environmental factors include the air temperature, the temperature of the surrounding surfaces, the air movement, the relative humidity, and the rate of air exchange (ventilation). Thermal comfort will also depend on the activity and the clothing worn by the individual, and the age, health status, gender, and the adaptation to the local environment and climate of the individual and the household (see, for example, Goromosov, 1968; WHO, 1984; ASHRAE, 2009). Other factors like household crowding and under-occupation will also have an influence. All these factors may be variable both for the individual and among members of the household during the day and over time.

While none of these factors remain stable, particularly in the home environment, and as it may not be possible to assess some, it is necessary for guidance to make some assumptions and to give safe limits. For thermal comfort in the home, it is the ambient air temperature that has been the main focus of guidance and of thresholds to protect health.

\subsection{WHO reports on thermal comfort}

The WHO guidance on thermal comfort in dwellings and the temperature range are frequently referred to, but without reference to the original source. A search of the WHO publications and archives produced various reports on 
the indoor environment and indoor housing environment. These referred to WHO Public Health Paper No. 33 (Goromosov, 1968), and, although not available in $\mathrm{WHO}$ databases, it appears that this provided the original basis for the WHO guidance. This report, entitled 'The Physiological Basis for Health Standards for Dwellings', includes a section on the thermal environment, and it is this that provided the basis for subsequent $\mathrm{WHO}$ guidance on the indoor air temperature range necessary to protect health, including the health of those more likely to be susceptible to high and low temperatures.

This 1968 report examined the evidence for the human body's powers of thermal regulation. It concluded that the human body can only compensate for a relatively small temperature range, a so-called 'zone of indifferent metabolism' - the range where human energy expenditure is minimal - and gave this range as from $15^{\circ} \mathrm{C}$ to $25^{\circ} \mathrm{C}$.

In 1982, a WHO Working Group (WHO, 1984) reviewed the evidence on air temperatures in the home and health. The report concluded that there was minimal risk to the health of sedentary people, such as the elderly, in housing in which the ambient air temperature is between $18^{\circ} \mathrm{C}$ and $24^{\circ} \mathrm{C}$. However, the report gives no references on which this revision of the temperature range was based ${ }^{1}$. The report also stated that there was insufficient data at that Working Group (see Collins et al., 1985). 
time on the impact of the indoor climate on high risk groups, such as older people, the handicapped and young children, to be able to develop indoor thermal parameters for housing at that time.

A subsequent WHO report (1987) adopted the 1982 range, as did a later WHO report on the health aspects of the indoor environment (WHO, 1990). While the 1987 report stated that no conclusion could be reached on the average indoor air temperate below which the health of the general population may be considered endangered, it did recommend that for certain groups such as the very old (although not specified, the report refers to studies on people over 65 years old) and the very young, there should be a minimum temperature of $20^{\circ} \mathrm{C}$. It also added that there was evidence that ambient air temperatures below $12^{\circ} \mathrm{C}$ posed a health risk for these susceptible groups (Collins et al., 1985 was referenced in the text).

\subsection{Evidence on temperature susceptible groups}

There have been various studies since the 1982 WHO report that have investigated which population groups may be more susceptible to temperatures at or beyond the thresholds of the WHO thermal comfort range. Collins (1986) reviewed the effects of different temperature ranges on the elderly (those over 65 years old). He used the term Comfort Zone for the temperature range $18-24^{\circ} \mathrm{C}$, although he suggests that an older person suffering from hypothyroidism may feel cold at $24^{\circ} \mathrm{C}$. Collins reported that at $16^{\circ} \mathrm{C}$ there was an increasing risk of respiratory disorders, and that significant 
blood pressure rises had been observed in the elderly at temperatures of $6^{\circ} \mathrm{C}$, $9^{\circ} \mathrm{C}$ and $12^{\circ} \mathrm{C}$, but not at $15^{\circ} \mathrm{C}$.

A recent cross-sectional study involving 148 patients suffering from Chronic Obstructive Pulmonary Disease found that their symptomatic health status was significantly worse when there were fewer days where the indoor temperature failed to reach and be maintained at $21^{\circ} \mathrm{C}$ for at least 9 hours (Osman et al., 2008).

A study into the impact of ambient temperatures on mortality in the Netherlands during 1979-1997 using mortality and temperature data, looked at the health effects of heat waves (Huynen et al., 2001). While not giving threshold temperatures, this study found that increases in heat-induced mortality occurred mainly in those of 65 years or more. Another study reviewed the association between heat and morbidity (McGeehin and Mirabelli, 2001) and found that those most susceptible to heat had certain chronic medical conditions such as cardiovascular and cerebrovascular diseases, diabetes, respiratory and renal diseases, Parkinson's disease, Alzheimer's disease and epilepsy.

At the other end of the age range, in a cross-sectional study using household survey and surveillance data, involving 9721 children less than 36 months old, child health and development were shown to be negatively affected by household energy insecurity (Cook et al., 2008). In this study, household 
energy insecurity was taken to have occurred when, over the previous twelve months, the household had been threatened with or experienced a utility shutoff, had an unheated or uncooled day, and/or used a cooking stove for heating.

\section{From guidance to measurement}

As for all the factors influencing thermal comfort, indoor air temperature is subject to considerable variation. As well as differing depending on the time of day, there are vertical and horizontal temperature gradients within a room at any one time. And, within a dwelling, ambient temperatures will vary from room to room depending on their use and orientation. As well as the ambient temperature (and the other the factors mentioned) thermal comfort will be affected by heat sources and colder surfaces within the dwelling, and by the season and the local climate.

For laboratory studies (such as that carried out by Collins and Hoinville, 1980), it is possible to follow a strict protocol for measuring the air temperature. For general housing surveys, however, strict protocols are less easy to devise, making it difficult to interpret and compare the findings. There are at least two alternatives - canvassing the perception of residents, and estimating thermal comfort. 


\subsection{Measuring perception of thermal comfort}

A practical solution for housing surveys has been to use the perception of thermal comfort rather than the measurement of ambient temperature. This approach has advantages as an individual's perception will include taking into account a wide range of factors, in particular those that are difficult to measure directly, that may contribute to thermal comfort. It also makes it possible to assess the perception of thermal comfort of individual members of a household, who will have different characteristics and different health risks.

This perception approach as a proxy for thermal comfort was used in the WHO Large Analysis and Review of European housing and health Status (LARES) project (Ormandy, 2009). This project involved collecting data on housing and household characteristics in representative samples of dwellings in eight cities across Europe. It provided substantial data on the conditions in 3373 dwellings and the health of their 8519 residents. At the design stage of the project it was decided that taking measurements of air temperature would be impractical and would produce misleading data that would not allow for dependable and comparable analyses. As well as the variable factors mentioned above, the surveys of the eight cities would be carried out at different times of the year, and the climate of each city differed. It was decided that perceived thermal discomfort could be identified based on whether, in response to a series of questions, an inhabitant (one per household) reported that there was a problem with temperature in the dwelling during the winter, summer, and/or spring/autumn season. If there was a positive response (ie, 'Seldom', 'Sometimes', 'Often', or 'Permanent'), for any 
season then a supplement question was put for each, asking whether it was because it felt 'Too Warm', 'Too Cold', or 'Both' (Ormandy (ed), 2009).

Table 1 - Residents' perception of thermal comfort and opinion of heating system (WHO LARES)

\begin{tabular}{|c|c|c|c|c|c|c|c|c|c|}
\hline & $\begin{array}{c}\text { Vilnius } \\
N=684\end{array}$ & $\begin{array}{c}\text { Bratislava } \\
N=338\end{array}$ & $\begin{array}{c}\text { Budapest } \\
N=447\end{array}$ & $\begin{array}{c}\text { Genev } \\
a \\
N=333\end{array}$ & $\begin{array}{c}\text { Bonn } \\
N=390\end{array}$ & $\begin{array}{l}\text { Angers } \\
N=427\end{array}$ & $\begin{array}{c}\text { Forli } \\
N=397\end{array}$ & 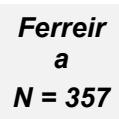 & $\begin{array}{c}\text { Total } \\
\mathbf{N}=3373\end{array}$ \\
\hline $\begin{array}{l}\text { Problems with } \\
\text { temperature in } \\
\text { summer }^{\circ}\end{array}$ & $31 \%$ & $46 \%$ & $62 \%$ & $30 \%$ & $22 \%$ & $22 \%$ & $60 \%$ & $60 \%$ & $39 \%$ \\
\hline $\begin{array}{l}\text { Too cold in } \\
\text { summer }\end{array}$ & $6 \%$ & $1 \%$ & - & $1 \%$ & $1 \%$ & $7 \%$ & - & $2 \%$ & $2 \%$ \\
\hline $\begin{array}{l}\text { Problems with } \\
\text { temperature in } \\
\text { spring/autumn }\end{array}$ & $55 \%$ & $33 \%$ & $16 \%$ & $13 \%$ & $10 \%$ & $15 \%$ & $5 \%$ & $50 \%$ & $27 \%$ \\
\hline Too cold & $90 \%$ & $69 \%$ & $63 \%$ & $49 \%$ & $86 \%$ & $72 \%$ & $61 \%$ & $20 \%$ & $67 \%$ \\
\hline $\begin{array}{l}\text { Both too warm } \\
\text { and cold }\end{array}$ & $6 \%$ & $23 \%$ & $33 \%$ & $26 \%$ & $11 \%$ & $20 \%$ & $33 \%$ & $79 \%$ & $28 \%$ \\
\hline $\begin{array}{l}\text { Problems with } \\
\text { temperature in } \\
\text { winter }^{\circ}\end{array}$ & $60 \%$ & $32 \%$ & $28 \%$ & $32 \%$ & $23 \%$ & $33 \%$ & $21 \%$ & $75 \%$ & $46 \%$ \\
\hline Too warm & $4 \%$ & $18 \%$ & $10 \%$ & $27 \%$ & $6 \%$ & $17 \%$ & $11 \%$ & $1 \%$ & $9 \%$ \\
\hline $\begin{array}{l}\text { Quality of } \\
\text { heating system* }\end{array}$ & 3.4 & 3.7 & 3.8 & 3.9 & 4 & 3.8 & 4 & 3.2 & 3.7 \\
\hline \multicolumn{10}{|l|}{$\begin{array}{l}\text { \% of annual } \\
\text { household } \\
\text { income/heating } \\
\text { system }\end{array}$} \\
\hline Up to $5 \%$ & $5 \%$ & $17 \%$ & $14 \%$ & $73 \%$ & $55 \%$ & $46 \%$ & $46 \%$ & $33 \%$ & $29 \%$ \\
\hline Over $20 \%$ & $46 \%$ & $21 \%$ & $26 \%$ & $1 \%$ & $1 \%$ & $4 \%$ & $2 \%$ & $1 \%$ & $19 \%$ \\
\hline $\begin{array}{l}\text { Rating of } \\
\text { heating costs: } \\
\text { expensive }\end{array}$ & $65 \%$ & $35 \%$ & $53 \%$ & $12 \%$ & $17 \%$ & $13 \%$ & $27 \%$ & $46 \%$ & $37 \%$ \\
\hline
\end{tabular}

${ }^{\circ}$ seldom/sometimes/often/permanent

* scale from 1 (highly dissatisfied) to 5 (highly satisfied)

Using the perception of an occupant in the LARES project made it possible to analyse the data to investigate for a relationship between some common diseases and symptoms and the main characteristics of energy efficiency, including residential thermal comfort (Ezratty et al., 2009a and 2009b). The eight cities have different characteristics, in particular socioeconomic, political, 
cultural and climatic differences. It was therefore important to take account of a possible 'city effect' that could have biased results from the analysis of the combined data from the eight cities. Therefore, the analyses of the combined data focusing on the energy issue included adjustment using two objective 'city indicators' - the mean outdoor temperature in July (the hottest month) and that in January (the coldest month) for each city.

It was found that, after adjustment for age, gender, socio-economic status and smoking, self-reported poor health was significantly associated with poor thermal comfort (Odds Ratio $(\mathrm{OR})=2.6\left[\mathrm{Cl}_{95}=2.1-3.1\right]$ ), inadequate weathertightness $\left(\mathrm{OR}=2.4\left[\mathrm{Cl}_{95}=2-3\right]\right)$ and mould and/or dampness problems $(\mathrm{OR}=1.7$ $\left.\left[\mathrm{Cl}_{95}=1.4-2\right]\right)$. Similar results were observed for specific diseases, after adjustment for relevant characteristics. Asthma attacks in the preceding 12 months were significantly associated with mould or dampness $(O R=1.7$ $\left.\left[\mathrm{Cl}_{95}=1.2-2.5\right]\right)$, poor thermal comfort $\left(\mathrm{OR}=1.5\left[\mathrm{Cl}_{95}=1-2.2\right]\right)$ and inadequate ventilation $\left(\mathrm{OR}=1.5\left[\mathrm{Cl}_{95}=1.1-2.2\right]\right)$. Allergies, hypertension, colds and sore throats, migraine or frequent headaches over the previous 12 months were also associated with poor thermal comfort (OR of $1.5\left[\mathrm{Cl}_{95}=1.3-1.7\right], 1.8$ $\left[\mathrm{Cl}_{95}=1.4-1.9\right], 1.4\left[\mathrm{Cl}_{95}=1.2-1.5\right]$ and $1.8\left[\mathrm{Cl}_{95}=1.6-2.1\right]$ respectively $)$, mould or dampness (OR of $1.3\left[\mathrm{Cl}_{95}=1.1-1.5\right], 1.2\left[\mathrm{Cl}_{95}=1-1.4\right], 1.3\left[\mathrm{Cl}_{95}=1.2-1.4\right]$ and $1.8\left[\mathrm{Cl}_{95}=1.7-2.3\right]$ respectively), and insufficient weather-tightness (OR of 1.1 $\left[\mathrm{Cl}_{95}=1.1-3\right], 1.2\left[\mathrm{Cl}_{95}=1.1-1.4\right], 1.2\left[\mathrm{Cl}_{95}=1.1-1.4\right]$ and $1.7 \quad\left[\mathrm{Cl}_{95}=2.1-2.5\right]$ respectively). Gastric and duodenal ulcers appear to be significantly associated with poor thermal comfort $\left(\mathrm{OR}=1.9 \quad\left[\mathrm{Cl}_{95}=1.6-2.5\right]\right)$ and poor 
weather-tightness $\left(\mathrm{OR}=1.6\left[\mathrm{Cl}_{95}=1.2-2\right]\right)$. (See Ezratty et al 2009a and 2009b.)

Although these results need to be confirmed by other studies, the LARES project shows that the use of occupant's perception of thermal comfort is a viable approach in housing and health surveys. There are, however, some limitations and caveats.

One limitation is age. It has been shown that the elderly may be relatively poor at discriminating temperature (eg, Watts, 1971; Collins and Hoinville, 1980; and Ezratty et al, 2009a and 2009b), and may feel comfortable at temperatures that could be unhealthy for them. At the other end of the age spectrum, as well as not being able to communicate, the very young have an under-developed thermoregulatory system. This limitation is particularly important as these two groups are susceptible to the temperatures outside the WHO thermal comfort range.

An important point is the phrasing and the understanding of the question(s) on which depends the responses. In the LARES project, the same validated questionnaire was translated in the different languages and tested before the beginning of the survey (see Bonnefoy et al, 2003). This meant that data from each of the eight cities could be compared. However, there does not appear to be an accepted protocol or standardised phrasing that would allow for comparison between surveys, unlike in this WHO LARES project. 


\section{Predicting Thermal Comfort}

Assessing thermal comfort can be done by measuring perception or by measuring ambient air temperatures, but other approaches are necessary for designing buildings and for estimating the thermal satisfaction of occupants. One approach is founded on laboratory research protocols originally developed by Fanger (1970) where subjects in controlled conditions gave their verdict on different temperatures. The present standards recommended by the American Society for Heating, Refrigerating, Air-conditioning Engineers (ASHRAE, 2009) uses thermal sensation scale based on Fanger's original work. (There are similar methodologies given by the Internal Organization for Standardization (ISO, 2005), and the Chartered Institute of Building Services Engineers (CIBSE, 2006.)

To assist designers, ASHRAE developed a formula for calculating the Predicted Mean Vote (PMV) and the Predicted Percent Dissatisfied (the PPD), ie, the percentage of people who would be uncomfortable with a particular thermal environment. The formula includes physiological variables and the estimated thermal load on the body to produce the PMV index. This PMV index predicts the 'mean response of a large group of people to the ASHRAE thermal sensation scale' (ASHRAE, 2009). This seven point scale ranges from 'Hot' through 'Neutral' to 'Cold', with a numbers used to represent the responses ('+3' through ' 0 ' to ' -3 '); as the PMV moves from zero in either a positive or negative direction, it indicates that there will be a greater percentage of people dissatisfied because they will be either too warm/hot or too cool/cold. The rationale behind this approach is aimed at minimising the 
number of uncomfortable (dissatisfied) people, although ASHRAE state that even with a PMV equal to 0 , about $5 \%$ of the people will be dissatisfied (ASHRAE 2009, 9.16).

This ASHRAE PMV-PPD approach is generally seen as being intended to produce indoor thermal environmental conditions that will be acceptable to a majority of occupants (AREN 3050, 2005), and, as already mentioned, is geared to predicting the response of a large group of people. While primarily used for working environments (offices and industrial buildings) it has been used in residential settings (de Dear et al., 1997; Mothibi BE, 2005). However, results of $90 \%$ thermal acceptability (as reported in de Dear et al) may not be considered appropriate for housing, particularly housing occupied by older people or young children. While the health of those in the working environment - the healthy population of working age - should be protected, it is the home environment that is used by the very young, the elderly, the sick and others susceptible to extremes of temperatures for other reasons. For such potentially temperature susceptible groups, estimating or predicting 'dissatisfaction' does not ensure the protection of their health.

One study has compared measured indoor temperatures with the occupant's perception of thermal comfort and with the PMV (Hong et al., 2009). This study collected self-reported thermal comfort (measured on a seven-point scale) and the indoor temperatures in the living room and in the main bedroom (recorded twice daily over 11 consecutive days) in 2500 dwellings. 
The aim was to investigate the impact of energy efficiency improvements, and study found that the 'whole house neutral temperature' (the temperature at which most residents felt thermal neutrality) rose from $18.9^{\circ} \mathrm{C}$ to $19.1^{\circ} \mathrm{C}$ following the improvements. They also compared this 'mean comfort vote' with the PMV, and found that the PMV gave a higher neutral temperature of $20.4^{\circ} \mathrm{C}$. However, the authors warn that, because of the specific socioeconomic characteristics of the participating households, caution is required in extrapolating any conclusions to the general population.

\section{Using tools to inform strategies}

The WHO guidance is directed to protecting health, particularly the health of the more susceptible members of the population. The methods for measuring thermal comfort are useful for surveys and studies, and predicting thermal comfort is important for informing designers of buildings. But what is also needed are practical tools to identify and prevent problems, and to inform and direct strategies.

Some methods are used for identifying potential problems associated with poor energy efficiency and susceptible occupants, each with different objectives, and so taking account of different factors.

Other methods focus on the building and its energy efficiency or performance. Some are used to predict the energy usage of new buildings, based on information on its construction and equipment; others are used to estimate the energy performance of existing buildings using assumptions. 
Energy Performance Certificates (EPCs) are now required in all European Union countries whenever a dwelling is sold or offered for rent (Directive 2002/91/EC). The Directive does not specify how each country should calculate the energy performance, but gives a framework of factors to be taken into account. This means that while the result, the EPC as issued by each EU country, appear the same or very similar, the underlying calculation may be different.

EPCs are, as the name implies, about energy and the 'running cost' of dwellings. There is no direct relationship with the health of occupiers, although the energy performance will be based on achieving thermal comfort as well as other average energy use (the Directive makes only one indirect reference to thermal comfort in para 16, p2). While these EPCs do not inform strategies, they do give information to prospective purchasers and tenants which may influence their decisions.

Fuel (or energy) Poverty (however defined) focuses on the household's ability to afford the energy needed for domestic and household purposes, including achieving and maintaining a state of thermal comfort within the dwelling. It is intended to provide a means to identify energy inefficient dwellings occupied by households with insufficient funds to afford the energy costs. While health is not specifically mentioned in any definition, maintaining indoor temperatures within the thermal comfort range implies protecting the health of the residents. 
A Fuel Poverty Indicator has been developed in England, using data from the 2003 English House Condition Survey (CLG, 2006) and the 2001 Census (ONS, 2004). This Indicator (CSE, 2011) is based on data from the EHCS to predict the risk of fuel poverty for different household types, and the results then applied to the 2001 Census data to predict the level of fuel poverty in defined areas (each of around 400 dwellings). It is intended to be used by those developing strategies.

There are also tools used to assess dwellings for potential threats to health, whether or not the dwelling is occupied or occupied by members of a susceptible group.

In England and Wales there is the Housing Health and Safety Rating System (HHSRS), (ODPM, 2006) which allows the assessment of a dwelling for potential health hazards including exposure to excess Cold or excess Heat. Annex D of the HHSRS Operating Guidance (ODPM, 2006) provides profiles of all the 29 hazards, and includes a summary of the potential for harm, and of the optimum conditions to avoid or minimise it. The HHSRS is an example of a methodology that has a clear health focus, which is used, both to inform strategies, including strategies to tackle fuel poverty (Jones, 2008), and to trigger action to reduce threats to health. 
Recently, several European countries have developed approaches that are health based, such as the creation of a new diploma to be Conseillers Médicaux en Environnement Intérieur (CMEI, 2011), (Medical Advisers on indoor Environment) in France and the Green Ambulances in Brussels (and various other places). These start from the health of the individual - where a patient presents with particular symptoms, such as a respiratory condition, that could be linked with dampness and/or cold, a referral can be made for an investigation of possible exposures and risks in the home environment.

\section{Strategies to protect health}

In 2006, WHO Europe organised a meeting, the aims of which included reviewing housing-related strategies directed at preventing threats to health posed by energy inefficiency and Fuel Poverty (WHO, 2006). The meeting recognised the need for two approaches; one essential, but short-term, and the other long-term.

The short term strategies are those directed to ensuring occupiers can afford to obtain sufficient energy to maintain their homes at healthy and comfortable temperatures. These include financial assistance paid direct to householders to supplement their available income; payments made to the supplier for the householder's energy; and controlling of the cost of energy either nationally or through social tariffs. While vitally important to protect susceptible households, and so reducing excess winter deaths and other temperaturerelated health effects, these are short term 'First Aid' measures and would not provide long term solution. 
The long-term strategies are those directed at improving domestic energy efficiency. The energy efficiency of new (yet to be built) housing can be controlled through building codes and regulations; this, however, will have a very slow impact as existing dwellings make up more than $90 \%$ of the housing stock of countries. This means that to be effective, these strategies should include action to improve the energy efficiency of the existing housing stock, particularly of older and probably most energy inefficient dwellings. These actions include making heating systems more energy efficient; making dwellings more air-tight (but avoiding problems of indoor air quality by ensuring a sufficient ventilation); and improving the thermal insulation of the dwelling. Such strategies should cover all housing sectors - the public and the private sectors, and both the rented and the owner-occupied.

The conclusion of the working group was that both short-term and long-term strategies were necessary to protect health, particularly the health of those most susceptible to temperatures outside the WHO thermal comfort range.

\section{Conclusions and perspectives}

The WHO guidance for air temperatures in the home are directed to protecting health, and in particular the health of those more susceptible to heat and/or cold. The guidance was based on evidence and has been supported by subsequent research. What is not clear is why there was a change from $15^{\circ} \mathrm{C}-25^{\circ} \mathrm{C}$ in the $\mathrm{WHO}$ referenced documents from the late sixties to $18^{\circ} \mathrm{C}-24^{\circ} \mathrm{C}$ in those published in the eighties, however, this latter 
range is supported by evidence and has been generally adopted as the thermal comfort range necessary to protect health.

Although not necessarily reliable for several susceptible groups - such as the elderly and the very young - the assessment of the occupiers' perception of thermal comfort is useful for surveys on the relationship between housing temperatures and health. However, as there does not appear to be an accepted protocol or standardised phrasing comparison between surveys using differently phrased questions is not possible.

The majority of the work on the inability to maintain indoor temperatures within the thermal comfort range has focused on the health impact of low temperatures. However, the potential health impact of high temperatures caused by heat-waves also needs to be taken into account, in particular for the most susceptible like the elderly or those with a chronic disease. High temperature is closely related to fuel poverty and energy inefficiency. The inability to afford sufficient energy for air conditioning, and the lack of insulation and protection from heat gain during events such as heat waves, can have a serious effect on health, particularly of susceptible groups (see for example Oudin Åström et al., 2011; Basu, 2009). This means that in some countries, 'fuel poverty' includes not being able to afford sufficient energy to maintain indoor temperatures within the thermal comfort range - both the upper as well as the lower end of the range. 
While air conditioning is seen as a solution in some countries, alternative passive solutions could be preferable non-energy using options. These include the installation and use of shades and blinds, the provision of insulation, consideration of the orientation of rooms and the dwelling, the provision of cool rooms, and the adaptation of the urban environment to reduce reflectivity (O'Neill et al., 2009). Such passive measures to avoid over-heating need to be incorporated into the design and refurbishment of dwellings and neighbourhoods to avoid reliance on air-conditioning (Bone et al., 2010). Whatever strategies are adopted directed at protecting the susceptible groups from extreme low and high temperatures should ensure that they do not compromise occupier health in other ways such as by reducing indoor air quality (Bone et al., 2010).

The threats to health from thermal discomfort are not the only potential health outcomes of a lack of access to affordable energy. An inadequate supply of energy may also mean an inadequate supply for other basic domestic needs such as for food storage and cooking, maintenance of personal and domestic hygiene, and artificial lighting. Each of these could result in threats to health such as food poisoning, spread of infections, slips and fall injuries, fire injuries (from candles or oil lamps) and carbon monoxide poisoning (from inappropriate unflued heat sources). In a recent report (Marmot Review Team, 2011), as well as increased excess winter death, the direct health impacts were given as including a variety of respiratory problems in children, negative impact on mental health for all ages, and exacerbation of conditions such as arthritis and rheumatism. It gave the indirect impacts as including negative 
affects on children's educational attainment and emotional well-being, affects on dietary opportunities, and an increased risk of accidents.

Energy efficiency improvements are generally promoted because of the reduction in carbon and greenhouse gas emissions, the saving in energy costs and the improvement in comfort for the householder. We have already shown that the WHO thermal comfort range is aimed at protecting health, and recent work by the UK Building Research Establishment (BRE) has demonstrated that improving energy efficiency has cost benefits for society (Nicol et al., 2010; Mason and Roys, 2011). The BRE looked at the cost to the UK National Health Service (NHS) of the physical health outcomes associated with low indoor temperatures, and then the reduction in those health outcomes that could be attributed to energy efficiency measures. This work suggests that improving the heating and insulation in all the energy inefficient dwellings in England would give a 'health cost-benefit' of some $£ 750$ million (approx 858 million $€$ ) every year by reducing the demands on the NHS.

The annual health cost attributable to energy inefficient dwellings should be compared to the one-off (single) cost of intervention. Such intervention costs will be variable, depending on the improvements necessary. A study in New Zealand investigated the value of the health, energy and environmental benefits of retrofitting insulation into 1350 dwellings in a low-income community and where at least one occupant had symptoms of respiratory 
disease (Chapman et al., 2009). It assessed a range of potential benefits, including reduced visits to GPs, hospitalisations, days off school, and days off work, together with energy savings and $\mathrm{CO}_{2}$ savings. The authors suggest that the total benefits in present value terms were one and a half to two times the cost of the provision and fitting of the insulation.

There are examples of studies in other countries into the cost to society of physical injuries (eg, Zaloshnja et al., 2005; Meerding et al., 2006), so it is conceivable that showing the cost-benefits of investing in energy efficiency measures is possible in other countries as in England.

While the term 'thermal comfort' is used to cover a variety of circumstances, the WHO guidance on a temperature range is directed to the home environment, aimed at protecting the health of residents, particularly of those most susceptible and fragile to temperatures outside that range. Energy efficiency strategies, and those directed at reducing fuel poverty and protecting against climate change should overtly acknowledge that the protection of health is not only rational, it attacks inequities, and has economic benefits for society.

This approach is not new, as Cicero said (106 BCE to 43 BCE) and is carved above a doorway to Walworth Old Town Hall in London, 'The health of the people is the highest law' (Fig 1). 


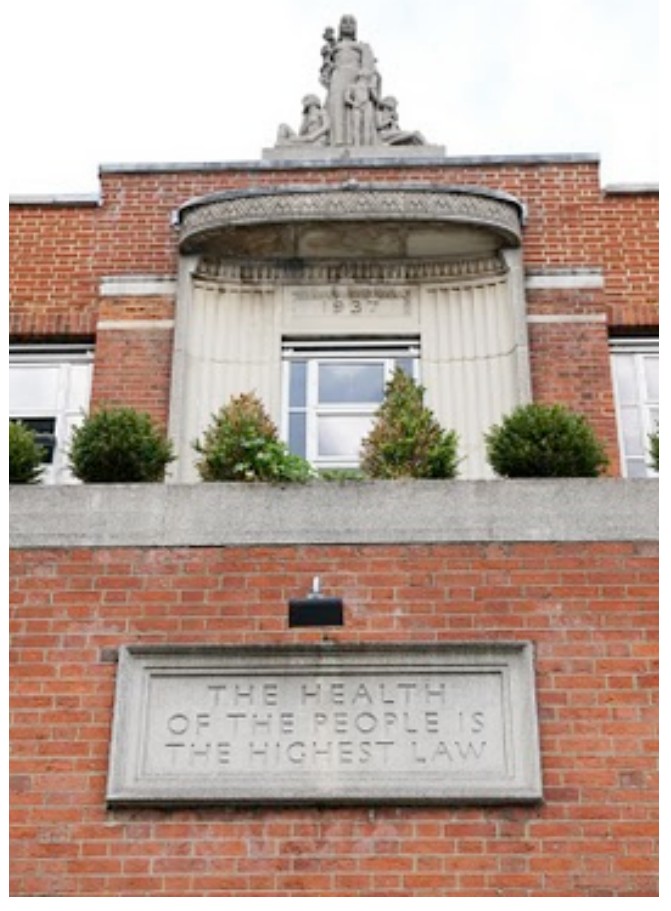

Fig 1 Walworth Old Town Hall, London

\section{Acknowledgements}

The authors are grateful for the very helpful comments and suggestions from the Editor and the Reviewers. 


\section{References}

AREN 3050 (2005) Environmental Systems for Buildings 1: Architectural Engineering Course, University of Colorado.

ASHRAE (2009). ASHRAE Handbook - Fundamentals: Chapter 9, Thermal Comfort. American Society of Heating, Refrigerating and Air-Conditioning Engineers Inc, Atlanta. http://www.ashrae.org

Basu R (2009) High ambient temperature and mortality: a review of epidemiological studies from 2001 to 2008. Environ Health 2009 Sep 16.8.40

Bone A, Murray V, Myers I, Dengel A, and Crump D (2010). Will drivers for home energy efficiency harm occupant health? Perspective in Public Health 2010 130: 233-237

Bonnefoy X, Braubach M, Krapavickaite D, Ormandy D, and Zurlyte I (2003) Housing conditions and self-reported health status: A study in panel block buildings in three cities of Eastern Europe, Journal of Housing and the Built Environment, 18329 - 352 (1566-4910)

Chapman R, Howden-Chapman P, Viggers H, O'Dea D, and Kenndy M (2009) Retrofitting houses with insulation: a cost-benefit analysis of a randomised community trial. J Epidemiol Community Health 2009;63:271-277

CIBSE (2006) Guide A: Environmental Design. Chartered Institute of Building Services Engineers, London.

CSE (2011). Fuel Poverty Indicator. Centre for Sustainable Energy, University of Bristol. http://www.fuelpovertyindicator.org.uk/

CLG (2006). English Housing Condition Survey, 2003. Communities and Local Government, London

CMEI (2011). Conseillers Médicaux en Environnement Intérieur. http://www.cmei-france.fr

Collins KJ, and Hoinville E (1980). Temperature requirements in old age. Building Services Engineering Research and Technology 1:165-172

Collins et al (1985). Effects of age on body temperature and blood pressure in cold environments. Clinical Science 69: 465-470

Collins KJ (1986), The Health of the Elderly in Low Indoor Temperatures. Unhealthy Housing: a diagnosis, Conference, University of Warwick, 1986 
Cook JT, et al (2008). A Brief Indicator of Household Energy Security: Associations with Food Security, Child Health, and Child Development in US Infants and Toddlers. Pediatrics 2008;122; e867-e875

de Dear R, Brager G, and Cooper D (1997) Developing an Adaptive Model of Thermal Comfort and Preference: ASHRAE RP-884. Macquarie Research Ltd, Macquarie University, Sydney, Australia. (See also http://aws.mq.edu.au/rp-884/ashrae rp884 home.html (accessed 27 September 2011.)

EU Directive 2002/91/EC on the energy performance of buildings. December 2002

Ezratty V, Duburcq A, Emery C, and Lambrozo J (2009a) Residential energy systems: links with socio-economic status and health in the LARES study. In Housing and Health in Europe: the WHO LARES project. Routledge, London

Ezratty V, Duburcq A, Emery C, and Lambrozo J (2009b) Liens entre l'efficacité énergétique du logement et la santé des résidents: résultats de l'etude européenne LARES. Environnement, Risques \& Santé Vol 8, $\mathrm{N}^{\circ} 6$

Fanger PO (1970). Thermal Comfort, Analysis and Applications in Environmental Engineering. Danish Technical Press, Copenhagen

Goromosov MS (1968). The Physiological Basis for Health Standards for Dwellings. Public Health Paper No.33. World Health Organization, Geneva

Hong SH, Gilbertson J, Oreszczyn T, Green G, Ridley I, and the Warm Front Study Group (2009) The correlation between temperature measure and perception of thermal comfort: A field study of thermal comfort in low-income dwellings in England before and after energy efficient refurbishment. Building and Environment 44 (2009) 1228-1236

Huynen MMTE, Martens P, Schram D, Weijenberg MP, and Kunst AE (2001). The Impact of Heat Waves and Cold Spells on Mortality Rates in the Dutch. Environmental Health Perspectives Vol 109, No.5, 463-470

ISO (2005) Ergonomics of the thermal environment - Analytical determination and interpretation of thermal comfort using calculation of the PMV and PPD indices and local 
thermal comfort criteria; ISO 7730:2005. International Organization for Standardization, Geneva.

Jones E (2008) Tackling fuel poverty using the Housing Health and Safety Rating System. Energy Efficiency Partnership for Homes, London

Marmot Review Team (2011) The Health Impacts of Cold Homes and Fuel Poverty. Friends of the Earth and the Marmot Review Team, London.

Mason V, and Roys M (2011) The Health Costs of cold dwellings. Building Research Establishment, Watford.

McGeehin MA, and Mirabelli M (2001). The Potential Impacts of Climate Variability and Change on Temperature-Related Morbidity and Mortality in the United States. Environmental Health Perspectives, Vol 109, Supplement 2, 185-189

Meerding WJ, Mulder S, and van Beeck EF (2006). Incidence and costs of injuries in the Netherlands. European Journal of Public Health, Vol 16, No.3, 271-277

Mothibi BE (2005) Optimising Energy for Thermal Comfort in Low-Cost Housing with Particular Reference to Bostwana. World Congress on Housing: Transforming Housing Environments through Design, 2005, Pretoria, South Africa.

Nicol S, Roys M, Davidson M, Summers C, Ormandy D, and Ambrose P (2010). Quantifying the Cost of Poor Housing. IHS BRE Press, Watford.

ODPM (2006) The Housing Health and Safety Rating System: Operating Guidance. Office of the Deputy Prime Minister, London

ONS (2004). 2001 Census. Office of National Statistics, London.

O’Neill MS, Carter R, Kish JK, Gronlund CJ, White-Newsome JL, Manarolla X, Zanobetti A, and Schwartz JD (2009) Preventing heat-related morbidity and mortality: New approaches in a changing climate. Maturitas 2009 October 20; 64(2): 98-103

Ormandy D (ed) (2009). The WHO LARES project: housing and health in Europe. Routledge Osman LM, Ayres JG, Garden C, Reglitz K, Lyon J, and Douglas JG (2008). Home warmth and health status of COPD patients. European Journal of Public Health Vol 18, No.4, 399-405 
Oudin Åström D, Bertil F, and Joaci R (2011) Haet wave impact on morbidity and mortality in the elderly population: A review of recent studies. Maturitas 2011 Jun 69(2) 99-105

Watts AJ (1971). Hypothermia in the Aged: A Study of the Role of Cold-Sensitivity. Environmental Health Research 5, 119-126

WHO (1984). The Effects of the Indoor Housing Climate on the Health of the Elderly: Report on a WHO Working Group. World Health Organization for Europe, Copenhagen

WHO (1987). Health Impact of Low Indoor Temperatures: Report on a WHO Meeting. World Health Organization for Europe, Copenhagen

WHO (1990). Indoor Environment: Health Aspects of Air Quality, Thermal Environment, Light and Noise. http://whqlibdoc.who.int/hq/1990/WHO_EHE_RUD_90.2.pdf (accessed 23 September 2011)

WHO (2006). Housing, Energy and Thermal Comfort: A review of 10 countries within the WHO European Region. World Health Organization for Europe, Copenhagen

Zaloshnja E, Miller TR, Lawrence BA, and Romano E (2005). The costs of unintentional home injuries. American Journal of Preventative Medicine, 2005: 28(1): 88-94 